Residência em

\section{Psiquiatria no Brasil: uma}

\author{
contribuição para 0
}

debate

\section{Psychiatry Residency in}

\author{
Brazill: a contribution to
}

\author{
the debate
}

A Psiquiatria é uma das especialidades que mais cresce na medicina, não só pelo aumento da demanda populacional como pelo surgimento constante de novos conhecimentos. 0 incremento de informações na área é tão grande que os periódicos especializados no mundo são, hoje, mais de 1.800 cadastrados apenas no PsycINFO da ISI ${ }^{\circledR}$. Isto, aliado ao incessante debate sobre a nosologia dos transtornos mentais, torna o estudo teórico da psiquiatria uma árdua tarefa.

Segundo a Organização Mundial de Saúde (OMS), em seu Relatório Sobre a Saúde no Mundo, 2001, os transtornos mentais acometem mais de 450 milhões de pessoas e respondem por $12,3 \%$ das causas de enfermidades e invalidez. Este número deve chegar a 562 milhões em 2020. ${ }^{1}$ Isso ocasionará uma enorme demanda aos serviços de psiquiatria, situação esta já acontecendo no Brasil.

Em 2002, a Associação Mundial de Psiquiatria (WPA) publicou o World Psychiatric Association Institutional Program on the Core Training Curriculum for Psychiatry, fruto de intenso debate entre especialistas e em grande parte baseado no resultado de um levantamento conduzido pela própria WPA sobre programas de residência em psiquiatria de todo o mundo - Statistical Report of the International Survey on Graduate Training in General Psychiatry. Nele, pela primeira vez, a WPA define recomendações mínimas para um currículo de especialização em psiquiatria, incluindo partes teórica e prática. Dentre estas, destacam-se uma duração mínima de três anos para residência em psiquiatria geral, em período integral e incluindo um mínimo de seis meses em neurologia e medicina interna, um mínimo de seis meses de estágios opcionais, ensino englobando todas as idades do ciclo de vida do ser humano, e obrigatoriedade de estágios especiais em emergências psiquiátricas, álcool e drogas, reabilitação, psiquiatria forense e distúrbios do aprendizado. ${ }^{2}$

Curiosamente, nenhuma instituição psiquiátrica do Brasil, o maior país da América Latina, respondeu ao questionário do levantamento feito pela WPA, no qual constam informações de centros de formação da Argentina, Uruguai, Chile, Colômbia, México e países de outros continentes. Dos programas avaliados por este relatório estatístico, $88,4 \%$ possuem três ou mais anos de duração, chegando-se a até seis anos, e 92,3\% têm pelo menos um mês de treinamento em neurologia. ${ }^{2}$

Os endereços eletrônicos de universidades brasileiras são, em grande parte, precários. Dificilmente um departamento de psiquiatria brasileiro tem uma página na internet, ainda mais dedicada à residência médica. A duração de dois anos exigida para a formação do psiquiatra no Brasil não cumpre a recomendação mínima de três anos proposta pela WPA, praticada na maioria dos países latino-americanos; nenhuma instituição brasileira oferece o mínimo de seis meses de treinamento em neurologia e medicina interna recomendado pela WPA.

Assim, verifica-se que os modelos de residência médica em 
psiquiatria no Brasil encontram-se defasados em relação à formação preconizada pela WPA e observada em diversos países, mesmo na América Latina. Esta insuficiente formação obriga os profissionais a buscarem cursos extracurriculares, cuja qualidade algumas vezes não pode ser garantida.

Impõe-se uma reestruturação dos programas de residência médica em psiquiatria no Brasil, a começar pelo tempo de formação mínima exigido, com critérios a serem estabelecidos pela Associação Brasileira de Psiquiatria e regulamentados pela Comissão Nacional de Residência Médica e pelo Ministério da Educação e Cultura.

O ensino da psicoterapia é assunto também controverso. Ao analisarmos os currículos de diversos países, podemos observar tendência em valorizar este conhecimento, preconizandose o contato do residente com suas diversas modalidades, inclusive na forma de subespecialização nos Estados Unidos, Canadá e Reino Unido. ${ }^{2-3}$ No Brasil, o ensino da psicoterapia encontra-se longe do ambiente universitário, concentrado em cursos livres ou ligados às sociedades específicas. O ensino de novas formas de terapia, validadas pela literatura, restringe-se a pouquíssimas escolas do sul e sudeste. ${ }^{4}$ A falta de regulamentação deste importante instrumento terapêutico tem levado à sua banalização, evidente com o surgimento quase diário de "psicoterapias" ligadas a sociedades religiosas, esotéricas e filosóficas, ou de "cursos técnicos".

Dessa forma, considerando o panorama acima exposto, tópicos apresentam-se como fundamentais para continuar o debate acerca da reestruturação da especialização em psiquiatria no Brasil:

1) Recomendações da WPA;

2) Duração mínima de três anos, considerando-se, porém, a possibilidade de maior duração em instituições com estrutura capacitada para tal;

3) Currículo flexível para adaptar-se às novas circunstâncias que surgem diariamente, considerando também as diferenças regionais de cada escola médica ou serviço;

4) Estágio em neurologia e sua duração;

5) Conteúdo programático diversificado, incluindo neurociências, psicopatologia, filosofia, teorias psicodinâmicas, psicofarmacologia, discussões de artigos científicos e bases teóricas da psiquiatria clínica;

6) Estágio psiquiátrico em todos os níveis de atendimento ambulatorial, enfermaria, reabilitação, hospital-dia e comunitário;

7) Obrigatoriedade do ensino de psiquiatria infantil, geriátrica e forense, de interconsultas e álcool e drogas;

8) Ensino teórico e prático de psicoterapia, possibilitando o contato do residente com linhas terapêuticas diversificadas, incluindo abordagens individual, conjugal, familiar e em grupo;

9) Carga horária reservada para áreas optativas, permitindo ao residente realizar intercâmbios, aprofundar-se em alguma área de interesse ou iniciar atividade de pesquisa;

10) Subespecialização através da regulamentação de programas de residência médica em psiquiatria infantil, psiquiatria geriátrica, psiquiatria forense, psicoterapia e outras.

Marcus Vinicius Zanetti e Bruno Mendonça Coelho Departamento de Psiquiatria da Faculdade de Medicina da Universidade de São Paulo (FMUSP)

Francisco Lotufo Neto

Programa de Residência Médica do

Departamento de Psiquiatria da Faculdade de Medicina da Universidade de São Paulo (FMUSP)

\section{Referências}

1. World Health Organization. The World Health Report 2001. Mental Health: new understanding, new hope. Geneva: World Health Organization; 2001.

2. World Psychiatric Association. Institutional Program on the Core Training Curriculum for Psychiatry. Virginia: World Psychiatry Association; 2002.

3. Basic Specialist Training Handbook. Royal College of Psychiatrists; 2003. Avaliable in URL: http://www.rcpsych.ac.uk/traindev/postgrad/ index.htm

4. Mello MF de. Terapia Interpessoal: um modelo breve e focal. Rev Bras Psiquiatr. 2004;26(2):124-30. 